\title{
Paulo Freire na formação de especialistas em educação e formação de adultos e intervenção comunitária
}

\author{
Alcoforado, Luís ${ }^{1}$
}

\begin{abstract}
Resumo
Ao longo das últimas décadas, a educação de Adultos tem vindo a reforçar a sua especificidade, quer enquanto problemática, quer enquanto campo de práticas, assumindo a importância de Paulo Freire como autor central deste processo. As Universidades, um pouco por todo o mundo, têm vindo a integrar-se neste esforço promovendo a construção de conhecimento e formando especialistas. Neste texto apresentamos experiências educativas ligadas ao Mestrado de Educação e Formação de Adultos da Universidade de Coimbra, que têm na obra de Paulo Freire um dos principais pontos de interesse e trabalho. Indicamos as opções teóricas e recenseamos os temas geradores escolhidos pelos/as alunos/as no planejamento e desenvolvimento de Círculos de Cultura.
\end{abstract}

Educação de Adultos. Formação de educadores. Paulo Freire.

\begin{abstract}
o
Durante las últimas décadas, la educación de adultos ha venido reforzando su especificidad, en cuanto problematica y en cuanto campo de prácticas, asumiendo la importancia de Paulo Freire como autor principal de este proceso. Las Universidades, un poco por todo el mundo, han tenido la responsabilidad de ser parte de este esfuerzo promoviendo la construcción del conocimiento y formando especialistas. En este trabajo se presentan experiencias educativas relacionadas con el Master en Educación y Formación de Adultos e Intervención Comunitaria de la Universidad de Coimbra, que tienen en la obra de Paulo Freire uno de los principales puntos de interés y de trabajo. Se indican las opciones teóricas y se enuncian los generadores elegidos por los estudiantes en la planificación y desarrollo de los círculos de cultura.
\end{abstract}

Educación de Adultos. Formacion de educadores. Paulo Freire.

\footnotetext{
1 Doutor em Ciências da Educação pela Universidade de Coimbra. É Professor na Faculdade de Psicologia e de Ciências da Educação da Universidade de Coimbra e Investigador do Grupo de Políticas Educativas e Dinâmicas Educacionais (GRUPOEDE) do Centro de Estudos Interdisciplinares do Século XX (CEISXX), uma Unidade de Investigação da Universidade de Coimbra e da Fundação para a Ciência e Tecnologia (FCT).
}

Interritórios | Revista de Educação Universidade Federal de Pernambuco Caruaru, BRASIL | V.2 | N.2 [2016] 


\section{1 desafio das universidades: construir um campo de conhecimento e formar profissionais para a Educação de Adultos}

Não será excessivo afirmar que a grande maioria dos processos educativos organizados, ao longo da História, se justificou por razões de estado e da administração, por obrigações determinadas pela teologia e pela fé e por necessidades evidenciadas pelas trocas comerciais (GRAFF, 1994). Já depois do século XVIII, no entanto, a este conjunto de razões, foram-se juntando, sucessivamente, motivos de desenvolvimento econômico mais geral e, principalmente, ideias de progresso democrático e social, traduzidos por uma fé firme na pessoa humana e pela necessidade de garantir uma efetiva igualdade de direitos e de oportunidades a todas as pessoas, em qualquer fase das suas vidas. Foi assim que surgiram as condições necessárias para o aparecimento de uma educação, ou pós-escolar, ou em substituição da escola que não se tinha podido frequentar, por qualquer razão, aparecendo a Educação de Adultos como um movimento social (JARVIS, 2001), ao qual foram aderindo sucessivas gerações de educadores, construindo a sua atividade numa militância e sentido ético de quem acreditava ser possível multiplicar as oportunidades e os direitos de todas as pessoas, independentemente da sua idade, desafiando-as a contribuir para a construção e fortalecimento das democracias, participar na edificação das identidades nacionais, maximizar o crescimento econômico e promover, decisivamente, a sua realização individual e social.

A Educação de Adultos foi-se organizando com o propósito de procurar responder a estes desafios civilizacionais, tendo a consciência plena que apenas dos seus contributos poderiam advir os recursos transformadores imediatos e necessários, para as pessoas e respetivas comunidades. Num primeiro momento, procurou fazê-lo, adotando os modelos tradicionais de ensino (LENGRAND, 1970), uma vez que o seu público era constituído por trabalhadores que dependiam, inteiramente, no que respeita à sua instrução, das instituições públicas ou particulares, dos quadros e corpos docentes oficiais, os quais, por sua vez, estavam submetidos a padrões tradicionais de cultura, de referências e de formação. Depois, porque estes modelos 
começaram a revelar uma evidente insuficiência de respostas para servir os interesses e características dos adultos, procurou construir a sua identidade numa distância assumida e progressiva das modalidades tradicionais de educação (LENGRAND, 1970). Foi, então, numa progressiva oposição a estruturas mentais, ideológicas, culturais e metodológicas conservadoras, que privilegiavam a herança cultural, o conformismo, a ordem e a infantilização do ato educativo, que veio, progressivamente, a constituir-se um novo tipo de Educação de Adultos. Teve origem e desenvolveu-se "fora dos caminhos tradicionais da escola e da universidade, nos colégios populares da Dinamarca, nas organizações de ensino mútuo, nas instituições de educação operária ou cooperativas, nos movimentos e associações de educação popular, etc... “ (LENGRAND, 1970, p. 49). Desta forma, a pessoa adulta foi deixando de ser entendida como objeto de formação para ser considerada como sujeito e agente da sua própria mudança e da transformação dos seus contextos de vida.

Não significava isto que a Educação de Adultos sempre fosse identificada como um conjunto de finalidades, metodologias e características universalmente fixadas. De Natale (2003) regista, pelo menos, dois grandes modelos, que, surgidos ambos até ao final do século XIX, cada um à sua maneira, marcaram duas diferentes formas de entender as atividades educativas para adultos. No primeiro, era "entendida como intervenção extraordinária, de carácter técnico e profissional e como instrumento de promoção social e de formação periódica" (DE NATALE, 2003, p. 48), enquanto no segundo modelo, que teve origem no pensamento e ação do bispo dinamarquês N. F. S. Grundtvig, se assumia que era indispensável construir uma Educação de Adultos essencialmente dirigida, "tanto para a consolidação da personalidade e para a elevação pessoal, como para o contínuo progresso e fortalecimento de uma organização social e democrática, inspirada no mais absoluto respeito das liberdades subjetivas" (DE NATALE, 2003, p. 48). Para este último campo de práticas era fundamental valorizar uma educação para a vida, reforçando, particularmente, a importância da família e das comunidades como espaços educativos. 
Ainda assim, mesmo com 0 aparecimento de muitas respostas educativamente inovadoras, principalmente até à segunda metade do século XX, a Educação de Adultos foi-se constituindo, sobretudo, como uma resposta para debelar os défices de conhecimentos de que as pessoas adultas eram portadoras, no âmbito dos contextos sociais que integravam, quer essas diferenças fossem de natureza cultural, religiosa, técnica, profissional, política, ou de exercício de cidadania. De Natale (2003, p. 54) cita Simpson, para concluir que

a Educação de Adultos, quer quando promovida por iniciativas públicas ou por associações privadas, foi sempre o lugar de encontro de três movimentos: o idealismo humanitário e cultural de pessoas de formação superior, que consideravam um dever comunicar os privilégios da educação aos menos afortunados; a propaganda nacionalista, ideológica ou religiosa; a vontade de indivíduos ou grupos que queriam beneficiar outros com as vantagens da educação.

Qualquer que fosse, no entanto, o sentido e força desses diferentes movimentos, cada vez se foi tornando mais visível que a Educação de Adultos, mesmo quando tinha como principal finalidade a superação dos eventuais défices de que as pessoas adultas eram portadoras, transportava consigo, desde sempre, uma assumida componente ideológica de mudança, indispensável para o cumprimento dos seus objetivos e finalidades, enquanto movimento social.

Assim, falar de Educação de Adultos passou a significar, também, falar de um movimento, que se foi afastando dos modelos tradicionais da escola de massas, que ousou percorrer outros caminhos, para além da instrumentalidade dos saberes escolares, vocacionais e profissionais, e que, progressivamente, se constituiu, desde os círculos de estudos da Dinamarca e Suécia, como projeto emancipatório e de Educação Popular, para posteriormente se alargar, com essa matriz identitária, a outras latitudes, como, por exemplo, à renovação de muitas das outras práticas europeias, às experiências de Highlander, nos Estados Unidos, criadas e dinamizadas por Miles Horton e, já na segunda metade do século $X X$, como veremos mais à frente, sair completamente 
renovada e revitalizada pelos incontornáveis contributos do pensamento e da praxis de Paulo Freire.

$\mathrm{Na}$ verdade, a partir do segundo grande conflito mundial do século $X X$ podemos identificar um decisivo impulso para a Educação de Adultos, que lhe permitiu assumir-se como domínio científico e como campo de práticas de identidade própria, com progressivo reforço de uma especificidade em permanente construção. Surgiram as primeiras investigações sistemáticas, apareceram os primeiros contributos teóricos de fôlego, realizaram-se os primeiros fóruns internacionais de reflexão e sistematização de atividades e apareceram os grandes programas de ação, que a procuraram enquadrar num desenvolvimento, tanto quanto possível, harmonioso e integrado. Todo este esforço foi ampliado pela UNESCO e pelas sucessivas Conferências Internacionais que este organismo organizou, procurando aglomerar os seus países membros num compromisso político com uma resposta educativa de especificidade própria, construída com base em novos referenciais ideológicos (fins) e tecnológicos (meios).

Para que estes objetivos fossem prosseguidos, tornava-se inadiável a participação das Universidades, desafiadas a contribuir para criar uma identidade epistemológica para este domínio e estimuladas a formar os profissionais/docentes capazes de construir e desenvolver um campo de práticas, concordante com essa especificidade teórica. As Universidades foram respondendo a este veemente apelo, preocupando-se com uma real abertura a novos públicos, inclusivamente através de programas de extensão, passando a incluir nos seus programas, conteúdos relacionados com o domínio científico da Educação de Adultos e, posteriormente, criando programas de pósgraduação, pensados especificamente, para a formação de especialistas capazes de atuar numa área já com identidade reconhecida.

A generalidade das Universidades portuguesas e a Universidade de Coimbra, em particular, responderam também a este desafio (ALCOFORADO, SOUSA, MOIO, SIMÕES, RITA e CARVALHO, 2007; ALCOFORADO e FERREIRA, 2011). No caso específico da Universidade de Coimbra, desde os anos setenta, do século $\mathrm{XX}$, que se verifica uma produção científica regular, 
acompanhada pela inclusão desta área nos programas de formação graduada e pós-graduada em Ciências da Educação. Posteriormente, no início deste século, foi criado o Mestrado em Educação de Adultos (atualmente com a designação de Educação e Formação de Adultos e Intervenção Comunitária) que, para além do objetivo de incrementar os trabalhos de pesquisa neste domínio, assumiu a responsabilidade de contribuir para reforçar a especificidade das práticas, preparando especialistas em planejamento, desenvolvimento e avaliação de atividades educativas com pessoas adultas.

Desde o primeiro ano de existência deste Mestrado que o pensamento e praxis de Paulo Freire foram incluídos nos programas de diferentes Unidades Curriculares, integrando, atualmente, os conteúdos de "Perspetivas Teóricas em Educação e Formação de Adultos" (contributos para as bases e princípios teóricos de construção desta problemática) e "Conceção, Desenvolvimento e Avaliação de Programas Educativos para Adultos" (através do planejamento e animação de Círculos de Cultura), devendo todos/as os/as Mestrandos/as, em pequenos grupos, escolher um tema e preparar um Círculo de Cultura que é, depois, desenvolvido na aula, com a participação de todos/as os/as colegas.

É esta experiência que vamos relatar neste texto. Começaremos por identificar as ideias-chave do pensamento de Paulo Freire que norteiam os nossos trabalhos, explicaremos como utilizamos a proposta dos Círculos de Cultura, indicaremos os temas que mais têm sido escolhidos pelos/as alunos/as, nas últimas edições e deixaremos exemplos de desenvolvimento, que foram propostos no último ano letivo.

\section{Trabalhar com Paulo Freire no mestrado de educação e formação de adultos e intervenção comunitária}

Comecemos por identificar os princípios teóricos (históricos, conceituais...) que procuramos explorar no nosso trabalho de aprendizagem conjunta Professor/Alunos/as, no âmbito da Unidade Curricular do Mestrado que procura fazer emergir um dos contributos mais originais e desafiadores deste campo de práticas. Ainda na década de cinquenta do século vinte, quando um pouco por toda a parte, se pensava e se desenvolvia uma 
Educação de Adultos muito calcada na educação escolar, baseada em conteúdos e modelos tradicionais de transmissão e avaliação, Paulo Freire empenhou-se em construir uma proposta específica para pessoas adultas, consubstanciada numa prática educativa e social, conhecida e difundida, alguns anos mais tarde, através da obra Pedagogia do Oprimido (FREIRE, 1972), ainda hoje um dos livros mais lidos e debatidos em todo o mundo.

Nesse trabalho, são enunciados os aspetos essenciais das novas propostas de trabalho pedagógico, integradas no todo coerente do que designa pedagogia do oprimido, entendida como "aquela que tem de ser forjada com ele (oprimido) e não para ele, enquanto homens e povos, na luta incessante de recuperação da sua humanidade. Pedagogia que faça da opressão e de suas causas objeto da reflexão dos oprimidos, de que resultará o seu engajamento na luta pela sua libertação, em que esta pedagogia se fará e refará" (FREIRE, 1972, p. 43). No entanto, a experiência da sua própria prática, o levara a constatar que nem sempre os oprimidos conseguem identificar a sua situação de opressão, normalmente construída e codificada na cultura dominante do opressor, sendo, por isso mesmo, na grande maioria das situações, impossível envolverem-se volitivamente na partilha e construção da sua pedagogia libertadora. Então,

a pedagogia do oprimido, que não pode ser elaborada pelos opressores, é um dos instrumentos para esta descoberta crítica - a dos oprimidos por si mesmos e a dos opressores pelos oprimidos, como manifestações da sua desumanização. (FREIRE, 1972, p. 44).

Partindo destes princípios fundadores e entendendo os homens e as mulheres como agentes do processo histórico, Paulo Freire foi construindo a sua praxis educativa, na convicção militante de que, quando estão em causa atividades de educação/formação que envolvam pessoas discriminadas, em função de diferenças ideológicas, construídas em resultado de estereótipos desenvolvidos e mantidos por culturas hegemônicas, o ato educativo terá que ser, simultaneamente, político e dialógico (FREIRE, 1972). Político, porque não há educação neutra (a ação cultural, ou está ao serviço da dominação, ou ao serviço da libertação de homens e mulheres!), devendo, por isso mesmo, 
qualquer ato educativo, traduzir-se numa construção e reconstrução contínua de significados da realidade, implicando ação sobre essa realidade; político, também, porque a sua finalidade deverá incluir a transformação de uma visão ingênua, responsável por situações de opressão, por uma visão crítica, que una os oprimidos numa ação promotora de mudança social.

Ao mesmo tempo e por outro lado, o ato educativo é transformado numa relação dialógica (porque ninguém educa ninguém, nem ninguém se educa sozinho), baseada numa convivência de igualdade entre o educador, os educandos e o objeto de conhecimento, devendo o primeiro assumir uma permanente atitude de humildade, amor e fé nos homens e nas mulheres, enquanto agentes do processo histórico e produtores de cultura e, por isso mesmo, capazes de problematizar a sua situação existencial e de se envolverem, de forma autônoma e responsável, na construção de uma nova realidade.

Para isto, os espaços e tempos formativos/educativos transformam-se em Círculos de Cultura (BRANDÃO, 1981; FEITOSA, 1999; ROMÃO, 2001), pois, num verdadeiro retorno aos princípios da Paidéia, a pedagogia deverá constituir-se como um processo de humanização da cultura, devendo a primeira tarefa do educador ser a da criação de condições para que ele e os educandos descubram, no contexto gerador, os temas geradores para a compreensão crítica da realidade. Estes são conceitos absolutamente centrais nas propostas freireanas e, naturalmente, incontornáveis na organização e desenvolvimento de um Círculo de Cultura, pelo que é, sempre, nossa intenção, ainda que sumariamente, envolvermo-nos numa breve descoberta do seu significado. Procurando entender as propostas de Paulo Freire, também através de Romão (2001, p. 137), "os temas geradores são elementos constitutivos de uma unidade epocal", entendida como o conjunto de ideias, conceções, valores, etc. que dominam uma determinada época. Assim, por exemplo, a globalização econômica e as fatalidades engendradas pelas ideologias, que a suportam, podem ser temas geradores e, por isso mesmo, desdobrarem-se em muitos outros temas de debate e em situações passíveis de análise coletiva. Só que estas situações apresentam-se, muitas vezes, para 
os excluídos, como codificadas na lógica de quem dispõe de condições de privilégio e poder, sendo que a primeira grande finalidade do processo educativo deverá consistir, por isso mesmo, em descodificar essas vivências, induzidas por uma consciência ingénua da realidade, rumo a novas atitudes e ações que elevem os participantes a agentes de mudança, incluídos num projeto político de sociedade que busque, continuamente, o máximo de igualdade de direitos, deveres e oportunidades e que conviva, de forma harmoniosa, com o mínimo de restrições de liberdades individuais. Teremos, assim, uma aposta, militante e intransigente, numa educação problematizadora, que procurará, permanentemente, a superação da realidade de partida, através de uma praxis transformadora ${ }^{2}$.

Nos seus últimos textos, Freire (1992; 1995; 1997) reatualiza um pouco a ideia e identificação dos oprimidos. Fala, com particular insistência, na necessidade de educar para a multiculturalidade e a diversidade, assumindo a importância das diferenças, sempre que sejam aditivas na construção de formas de vida baseadas na cooperação e na solidariedade, possibilitando a criação de uma cidadania planetária, suportada numa ética integral de respeito por todos os seres vivos que partilham o planeta (FREIRE, 1995).

Por outro lado, continua a militância intransigente contra a constatação recorrente de diferenças que criam, muitas vezes, ideologias discriminatórias (económicas, de cultura, de raça, de género...), acreditando que elas são geradas, naturalmente, pelas culturas hegemónicas, interessadas em perpetuar a sua situação de favor. Quando tal acontece, repete, convictamente, que "é impossível pensar na superação da opressão, da discriminação, da passividade, ou da pura rebelião que elas engendram, primeiro, sem uma compreensão crítica da História e, segundo, sem projetos de natureza políticoideológica no sentido da transformação ou da reinvenção do mundo" (FREIRE, 1995, p. 32). Logo, é necessário manter e atualizar o princípio de que, em

\footnotetext{
${ }^{2} \mathrm{Na}$ linha do que sugere Paulo Freire e, entre outros autores, José Eustáquio Romão, se as palavras geradoras são a metodologia de trabalho mais adequada para a Alfabetização de Adultos, os Temas geradores são muito mais indicados para situações de Pós-alfabetização, Animação Social e Educação Continuada e Intervenção Comunitária. Procurando criar situações educativas próximas da realidade dos/as nossos/as Mestrandos/as, optamos por basear os "nossos" Círculos de Cultura em temas geradores, eles próprios destinados a criar experiências problematizadoras e, desejavelmente, criadoras de condições de mudança.
} 
qualquer atividade educativa ou formativa, mormente daquelas destinadas a pessoas adultas, qualquer aprendizagem tem sempre que ser acompanhada de uma leitura do mundo (FREIRE \& MACEDO, 1994), traduzida em atitudes problematizadoras, na interpretação crítica da realidade e na sua superação.

No seu livro autobiográfico Cartas a Cristina, Freire (2002) estabiliza a dimensão axiológica que deve orientar qualquer processo educativo, reafirmando a centralidade atribuída à Liberdade, à Democracia, à Justiça e à Vocação para Ser Mais. Entende liberdade não como um presente que alguém nos oferece, mas como um direito que ora conquistamos, ora preservamos, ora aprimoramos, ora perdemos, dependendo do que fizermos com os momentos atuais.

Assim, a contínua humanização, das pessoas e das comunidades obriga a uma luta permanente pela superação dos obstáculos ao controlo racional da nossa vida, criando condições estruturais que tornem possível a permanente construção de uma sociedade mais democrática, capaz de se defender, punindo os infratores com justiça e rigor, capaz de falar, de protestar e permanentemente disposta a lutar pela realização da justiça (FREIRE, 2002). Em síntese, uma sociedade progressivamente mais democrática, onde todos os problemas se resolvam sempre com um aprofundamento dos processos democráticos, jamais substituídos por situações de exceção.

Mais que um método, o que Paulo Freire procura deixar-nos é uma agenda educativa de compromisso para a construção de uma Educação Popular, ao serviço de um desenvolvimento integrado e sustentável e da humanização das pessoas, das comunidades e da sociedade. Uma agenda, um corpus teórico e uma praxis que dialogam com outras ideias e que nas nossas experiências de ensino aprendizagem, no Mestrado, fazemos dialogar com outros contributos teóricos e propostas de intervenção educativa que, cada uma à sua maneira, têm vindo a influenciar a construção da especificidade da área da Educação de Adultos.

Um primeiro exercício de diálogo leva-nos a uma reflexão conjugada sobre as ideias de Paulo Freire, John Dewey e Jürgen Habermas. Na verdade, ainda que não tenham sofrido influências mútuas diretas, estes três autores 
revelam várias semelhanças e complementaridades, pelo que constitui um desafio heurístico de elevado interesse fazer a leitura comparada dos respetivos contributos.

É exatamente este exercício que se propuseram fazer Morrow; Torres (1998, p. 127), argumentando que,

para Dewey, Freire e Habermas, a educação não diz respeito apenas à educação, mas também à formação e à expansão da democracia e da cidadania democrática. Mais claramente ainda que a filosofia política de Dewey, as filosofias políticas de Freire e Habermas não temem o reconhecimento de que a democracia tem lugar no contexto do capitalismo, criticando ambos as relações sociais capitalistas, muito embora rejeitem noções simplistas sobre a revolução da classe trabalhadora ou alternativas socialistas. Tanto Freire como Habermas se centram na dominação e na exploração, enquanto conceitos (capitalismo tardio, capitalismo dependente), mas estão essencialmente preocupados em apreender os elementos subjetivos e comunicacionais das relações de poder interpessoais, bem como as possibilidades da sua transformação.

Entendendo a pedagogia crítica, através da confluência dos contributos de Freire e Habermas, Morrow \& Torres (1998) afirmam que a sua premissa fundamental é a de que, da história das relações sociais presentes na formação tanto do educador como do estudante, emergem obstáculos cruciais à aprendizagem e esses obstáculos são, na sua maioria, invisíveis, pois encontram-se interiorizados no self dos participantes e reproduzem-se nas relações que definem a educação como atividade social. Então, tanto para Freire como para Habermas, qualquer proposta educativa crítica tem que ser orientada para a remoção desses obstáculos e a transformação das relações sociais existentes.

Por outro lado, ainda que reforçando a ideia da influência de Dewey em Paulo Freire e a identidade de princípios com a escola russa de psicologia, iniciada por Vigotsky, Gadotti (s/d, p. 18) encontra, igualmente, muitos pontos em comum com o pensamento de Carl Rogers, pois, mesmo não defendendo a não diretividade na educação, existe em Freire uma clara opção por princípios rogerianos, desde a "liberdade de expressão individual, à crença na 
possibilidade de os homens resolverem, eles próprios, os seus problemas, desde que motivados interiormente para isso". Assim, pelo que fica dito, apesar das óbvias diferenças entre estas propostas teóricas, com influência decisiva na construção de uma especificidade para a Educação de Adultos, será pacífico aceitar a existência de pontes e denominadores comuns, que nos desafiam a uma leitura mais sustentada do domínio, na atualidade, e a um envolvimento numa (re)construção permanente das práticas e dos respetivos modelos de suporte.

É tudo isto que procuramos explorar no segundo semestre, na Unidade Curricular de Conceção, Desenvolvimento e Avaliação de Programas Educativos para Adultos, desafiando os nossos alunos, após identificação com todos estes contributos teóricos, a planejarem e desenvolverem Círculos de Cultura.

\section{Paulo Freire nos programas do mestrado em educação e formação de adultos e intervenção comunitária da universidade de Coimbra: um desafio para repensar os temas e as práticas educativas}

Logo na primeira aula do novo semestre letivo, impomos a nós próprios o desafio de animar um Círculo de Cultura sobre o Tema Gerador "Liberdade". Começamos por pedir aos alunos que reflitam individualmente sobre o que significa, para eles, liberdade ${ }^{3}$. De seguida pedimos que formem pequenos grupos e procurem consensos, até chegarmos a um acordo generalizado do grupo (normalmente entre doze e quinze alunos/as) sobre o que significa liberdade. Escrevemos e projetamos (ou fazemos um poster) com este entendimento coletivo de liberdade.

Num novo momento, procurando problematizar este entendimento inicial, através de um confronto com codificações reconhecidas da liberdade, iniciamos a projeção de imagens famosas identificadas com o tema (estátua da

\footnotetext{
${ }^{3}$ Normalmente, para iniciar esta reflexão individual, usamos uma das histórias da Mafalda, da autoria de Quino. Nessa pequena tira, Mafalda encontra uma Menina, na praia e pergunta-lhe como se chama. Quando a Menina Ihe diz que se chama Liberdade, Mafalda fica em silêncio, sem saber muito bem o que dizer. Então a Liberdade diz-lhe: pronto! Já tiraste as tuas conclusões estúpidas? É que toda a gente tira conclusões estúpidas quando me conhece!
} 
liberdade, em Nova lorque; pintura "a liberdade guiando o povo" de Lacroix; fotografias de momentos célebres de repressão, ou libertação, individual e coletiva), pedindo ao grupo e a cada um/a dos/as presentes que expresse a sua leitura das imagens e o que encontra nelas que se relacione com o seu (e do grupo) entendimento de liberdade. Numa outra fase, selecionamos um conjunto de poemas que os/as alunos/as declamam (exemplos: "Liberdade" de Fernando Pessoa; "Operário em Construção”, de Vinícius de Morais) e canções (exemplo: "Ma Liberté", de Georges Moustaki), pedindo comentários e incentivando debates sobre o entendimento de liberdade presente nestes textos, encontrando semelhanças e diferenças com a definição do grupo.

Por fim, pedimos que reflitam demoradamente sobre a sua definição inicial, que a alterem, se assim entenderem, estabilizem um compreensão final e elaborem projetos pessoais e grupal de ação, que Ihes permita incrementar continuamente a sua liberdade individual, de grupo e da comunidade que integram.

Numa das últimas edições desta Unidade Curricular, os/as alunos/as fixaram-se num sentido que identifica liberdade como algo que está em contínua construção, retirando da nossa ação diária obstáculos de natureza externa, tais como influências/dependências, diferenças culturais e linguísticas e limitações económicas, mas também obstáculos de natureza interna, como impulsos, hábitos, ignorâncias e preconceitos. Elaboraram e sequenciaram um programa de remoção progressiva de alguns destes obstáculos.

Para as aulas seguintes propomos que sejam eles/as próprios/as, após várias conversas na aula e nos intervalos, a identificar temas geradores e a planejarem e desenvolverem Círculos de Cultura, ou seguindo os princípios orientadores da experiência que acabaram de viver, ou enriquecendo as atividades com princípios teóricos oriundos dos contributos estudados. Organizando-se em pequenos grupos de três, ou quatro elementos, assumem a responsabilidade de todas as propostas de atividades.

Mesmo que haja, de forma predominante, uma aproximação à experiência anteriormente vivenciada, esta opção metodológica tem-se revelado uma surpresa muito significativa. Em primeiro lugar, porque é percebida pelos 
alunos como verdadeiramente diferente das suas referências anteriores. Depois porque lhe reconhecem uma inegável adequação às caraterísticas e necessidades das pessoas adultas.

Por fim, porque se dedicam, normalmente, de forma muito envolvente, à sua preparação e animação. Por tudo isto, parece-nos importante recensear aqui, os temas geradores escolhidos nos últimos anos e dar exemplos concretos do seu desenvolvimento.

Tabela1: Temas geradores, justificações e ideias orientadoras dos Círculos de Cultura

\begin{tabular}{|c|c|c|}
\hline TEMA GERADOR & JUSTIFICAÇÃO & IDEIA ORIENTADORA \\
\hline Amor & $\begin{array}{l}\text { À mulher é ainda, muitas vezes, } \\
\text { destinado um papel secundário e } \\
\text { de menor poder, nas relações } \\
\text { amorosas }\end{array}$ & $\begin{array}{l}\text { Debater criticamente os } \\
\text { estereótipos relacionados com a } \\
\text { mulher e o amor }\end{array}$ \\
\hline Direitos humanos & $\begin{array}{l}\text { Ainda existem muitos lugares } \\
\text { onde os direitos humanos não } \\
\text { são respeitados, muitas vezes em } \\
\text { situações concretas, bem } \\
\text { próximas de nós. }\end{array}$ & $\begin{array}{l}\text { Encontrar formas de refletir sobre } \\
\text { a importância dos Direitos } \\
\text { Humanos, a sua atualidade e } \\
\text { maneiras de incrementar a sua } \\
\text { presença nos nossos espaços de } \\
\text { vida e no mundo }\end{array}$ \\
\hline Gentileza & $\begin{array}{l}\text { "Gentileza é um gesto de cuidado } \\
\text { com o outro e com a vida", } \\
\text { ajudando a resolver muitos } \\
\text { conflitos. }\end{array}$ & $\begin{array}{l}\text { É necessário praticar a gentileza } \\
\text { com todos e em todas as } \\
\text { situações, esperando que a } \\
\text { pratiquem conosco, tornando } \\
\text { todas as situações de vida um } \\
\text { pouco mais humanizadas. }\end{array}$ \\
\hline $\begin{array}{l}\text { (Des)lgualdade de } \\
\text { Oportunidades entre } \\
\text { Homens e Mulheres }\end{array}$ & $\begin{array}{l}\text { A desigualdade entre homens e } \\
\text { mulheres atravessa todas as } \\
\text { áreas da sociedade. }\end{array}$ & $\begin{array}{l}\text { Refletir sobre situações concretas } \\
\text { de desigualdade no trabalho, na } \\
\text { política, na economia e na família, } \\
\text { sugerindo formas de minorar } \\
\text { progressivamente as situações de } \\
\text { desigualdade. }\end{array}$ \\
\hline Violência Doméstica & $\begin{array}{l}\text { A realidade mostra-nos que este } \\
\text { tema é uma realidade muito } \\
\text { presente, em Portugal, na } \\
\text { atualidade. }\end{array}$ & $\begin{array}{l}\text { Tomar consciência dos tipos de } \\
\text { violência doméstica, das formas } \\
\text { como é silenciada e denunciada e } \\
\text { identificar algumas estratégias } \\
\text { para a ultrapassar. }\end{array}$ \\
\hline $\begin{array}{l}\text { Extinção de Profissões } \\
\text { no mundo rural }\end{array}$ & $\begin{array}{l}\text { O interior do país, principalmente } \\
\text { as áreas mais rurais estão a } \\
\text { envelhecer e a ficar } \\
\text { desertificadas, levando à extinção } \\
\text { de várias profissões tradicionais }\end{array}$ & $\begin{array}{l}\text { Refletir sobre a possibilidade de } \\
\text { manter e recuperar algumas } \\
\text { profissões, através de projetos } \\
\text { integrados de Desenvolvimento } \\
\text { Local }\end{array}$ \\
\hline
\end{tabular}

Fonte: Mestrandos/as em educação 
Juntamos na tabela 1 os temas geradores, as justificações para a sua escolha e as ideias principais que orientaram o planejamento dos círculos de cultura organizados pelos/as alunos/as nos dois últimos anos letivos. Reafirmamos que após o enquadramento teórico anteriormente descrito, deixamos a escolha dos temas geradores e a organização e desenvolvimento das atividades, completamente à iniciativa dos/as alunos/as. A função de Professor da disciplina, durante estas atividades, vai variando, conforme as situações, de mais um membro do grupo e, por isso mesmo, elemento ativo dos círculos de cultura, a uma posição de observador não participante.

Procuremos agora, com recurso ao exemplo de um Círculo de Cultura, em concreto, ilustrar as propostas educativas dos/as mestrandos/as. Recorremos, para isso, ao Círculo com o tema gerador "Direitos Humanos", até por ter sido, da sequência apresentada na tabela, o último a ser desenvolvido. Uma primeira ideia que os/as aluno/as pretenderam trazer para debate foi o conceito de paz. A partir de um poema de uma criança sobre a paz, iniciaram a uma análise crítica da relação entre a ausência da violência e da guerra como condição para que os seres humanos possam experienciar sentimentos de segurança, de liberdade e de incentivo à participação para a construção do bem comum. Relembrou-se o momento histórico de aparecimento do documento da Declaração Universal, recordando a sua relação com o final da barbárie e a esperança de construção de um mundo de concórdia à escala planetária.

No decorrer subsequente das atividades, foram sendo estabelecidas ligações diretas entre uma seleção de alguns artigos da Declaração com imagens e informação relativas à sua (não) observação em diversos locais do mundo, para terminar com a famosa frase de José Saramago "toda a gente fala de direitos humanos e ninguém de deveres, talvez fosse importante inventar um Dia dos Deveres Humanos". Todos foram desafiados, então, a encontrar uma possível proposta de deveres que podiam ser incluídos numa agenda para a implementação de uma efeméride com estas caraterísticas.

Sem pretendermos ser exaustivos, parece-nos interessante referir o aproveitamento posterior do Círculo com o tema "Violência Doméstica". Como uma das mestrandas era formadora da área de Cidadania e Profissionalidade, 
de um grupo de mulheres adultas envolvidas num curso de Educação e Formação de Adultos de nível Secundário, decidiu explicar ao grupo a experiência que tinha desenvolvido no âmbito do Mestrado. Perante o grande interesse demonstrado pelas pessoas envolvidas no curso, animou um Círculo com o mesmo tema gerador, com aquele grupo e, perante os resultados conseguidos, os Círculos de Cultura passaram a ser a forma de trabalho predominante, naquela área curricular, ao longo do que restava do curso. Esta situação, em particular, apenas corrobora o sentimento muito positivo que os/as alunos/as do Mestrado e atuais/futuros especialistas de Educação de Adultos e Intervenção Comunitária experienciam com as propostas educativas de Paulo Freire e a pertinência da sua aplicabilidade na realidade portuguesa da atualidade. Nas palavras de um dos grupos, "os Círculos de Cultura assumem-se como uma metodologia capaz de colocar em reflexão crítica assuntos e temas do quotidiano dos educandos, auxiliando-os a compreenderem melhor a sua realidade, a sua intervenção e a sua participação nessa realidade".

\section{Notas Conclusivas}

A afirmação da Educação de Adultos como domínio científico e campo de práticas, com especificidade própria, apela a um envolvimento das Universidades, numa assunção plena de quatro responsabilidades principais: promover a constituição de equipas de pesquisa capazes de contribuir para a (re)conceptualização teórica contínua da Educação de Adultos, enquanto problemática; favorecer a produção e comunicação especializada de conhecimento; incluir a Educação de Adultos em todos os programas de Ciências da Educação e de Formação de Docentes, de graduação e pósgraduação, ajudando a formar os especialistas necessários a práticas que, desde há muito tempo, estão identificadas como possuindo uma identidade em permanente construção; usar todas estas atividades para contribuir na construção de comunidades ecoeducativas, capazes de induzir uma progressiva humanização de todos os seus membros. 
Dada a importância que o pensamento e a obra de Paulo Freire assumiram para este domínio, é cada vez mais comum encontrarmos a sua presença nas atividades de pesquisa e ensino/aprendizagem, particularmente nos programas de pós-graduação de inúmeras Universidades, um pouco por todo o mundo. O nosso caso é apenas mais um programa de formação, ao nível de Mestrado, que inclui as propostas do grande pensador e pedagogo, em diálogo com outros contributos, como mais um desafio aos/às alunos/as e futuros/as especialistas para se tornarem profissionais capazes de melhor responder aos três grandes desafios que a Educação de Adultos deve enfrentar, nos dias de hoje: envolver quem mais precisa; encontrar respostas que melhor se adequem às necessidades de mudança das pessoas e das comunidades; desencadear os impulsos emancipatórios necessários para garantir o ser mais de homens e mulheres envolvidos no seu processo de humanização contínua.

Aceitando o desafio que o próprio Paulo Freire nos lançou, é fundamental que partilhemos a leitura e reinvenção que vamos fazendo da sua obra nas nossas práticas de pesquisa e de ensino aprendizagem. Por um lado será a melhor forma de mantermos viva a sua herança e, por outro lado, conhecer, refletir e dialogar sobre diferentes abordagens, será a única maneira de o convocar para o empreendimento inadiável de trazer dignidade e credibilidade para a Educação de Adultos.

\section{Referências}

ALCOFORADO, L.; FERREIRA, S. M.. Educação e Formação de Adultos. Nótulas sobre a necessidade de descomprometer a Cinderela, depois do beijo do Príncipe Encantado. In Alcoforado, L. e outros. Educação e Formação de Adultos: políticas, práticas e investigação. Coimbra: Imprensa da Universidade de Coimbra, p. 7-20, 2011.

ALCOFORADO, L.; SOUSA, C.; MOIO, I.; SIMÕES, J.; RITA, R.; CARVALHO, V.. Transição para o trabalho de licenciados em Ciências da Educação pela FPCEUC, com estágio curricular na área de Educação de Adultos. Revista Portuguesa de Pedagogia, 41(3), p. 375-388, set./dez. 2007.

BRANDÃO, C. R.. (1981). O que é Método Paulo Freire? São Paulo: Brasiliense, 1981. 
DE NATALE, M. L.. (2003). La edad adulta, una nueva etapa para educarse. Madrid: Narcea, 2003.

FEITOSA, S.. (1999). Método Paulo Freire - Princípios e práticas de uma concepção popular de educação. Disponível em www.paulofreire.org.

FREIRE, P.. Pedagogia do Oprimido. Porto: Afrontamento, 1972.

Pedagogia da Esperança: um reencontro com a Pedagogia do

Oprimido. São Paulo: Paz e Terra, 1992

Política e Educação. São Paulo: Cortez, 1995

Pedagogia da Autonomia. Saberes necessários à prática educativa.

São Paulo: Paz e Terra, 1997.

Cartas a Cristina. Reflexões sobre a minha vida e a minha praxis. São Paulo: UNESP, 2002.

FREIRE, P.; MACEDO, D.. Alfabetização: leitura do mundo, leitura da palavra. São Paulo: Paz e Terra, 1994.

GADOTTI, M.. A voz do biógrafo brasileiro. A prática à altura do sonho. Disponível em www.paulofreire.org s/d.

GRAFF, H.. Os Labirintos da Alfabetização. Reflexões sobre o passado e o presente da alfabetização. Porto Alegre: Artmed, 1994.

JARVIS, P.. Introduction: Adult Education - an ideal for modernity? In Jarvis, P.

Twentieth Century Thinkers in Adult \& Continuing Education. Londres: Kogan Page, p. 1-11, 2001.

LENGRAND, P.. Introdução à Educação Permanente. Lisboa: Livros Horizonte, 1970.

MORROW, R. A.; TORRES, C. A.. Jürgen Habermas, Paulo Freire e a Pedagogia Crítica: Novas orientações para a Educação Comparada. Educação, Sociedade \& Culturas, $n^{\circ} 10$, p. 155-174, 1998. 